\title{
Significados Posibles de la Depresión en el Mundo Contemporáneo: Una Lectura Fenomenológica Mundana
}

\section{Possible Meanings of Depression in the Contemporary World: A Worldly Phenomenological Reading}

\author{
Virginia Moreira \\ Universidade de Fortaleza
}

\begin{abstract}
Este artículo ${ }^{1}$ presenta una lectura fenomenológica crítica de la depresión en el mundo contemporáneo, basada en un proyecto de investigación transcultural acerca de la depresión en Brasil, Chile y Estados Unidos. Para comprender el fenómeno patológico, la autora se sustenta en la perspectiva de la Psicopatología Crítica, que incluye tanto la dimensión cultural como la endógena y situacional. Si se entiende la depresión de forma mundana, es decir, en la intersección entre el hombre y el mundo, su etiología, entonces, se comprenderá de manera antropológica, sociológica y política, y no sólo individual. Partiendo de esa premisa, el artículo aborda las siguientes preguntas: ¿Cuál es el significado actual de la depresión como manifestación psicopatológica, constituida mutuamente con la cultura a partir de una perspectiva mundana?; ¿Qué ideología sustenta la experiencia de la depresión en las culturas brasileña, chilena y norteamericana?; y por último, ¿Cuál es el significado ideológico y cultural de la depresión en el mundo contemporáneo?
\end{abstract}

Palabras Clave: depresión, psicopatología crítica, fenomenología mundana.

\begin{abstract}
This article presents a critical phenomenological critical reading of depression in the contemporary world, based on a cross-cultural research project on depression in Brazil, Chile and the United States. In order to understand the pathological phenomenon, the author uses the Critical Psychopathology's perspective, which includes the cultural, the endogenous and the situational dimensions. If depression is understood in a "worldly way", as the intersection between man and the world, then its etiology can be considered as anthropological, sociological, and political, and not purely individual. Starting with this assumption, the article addresses the following questions: What is the current meaning of depression as a psychopathological manifestation, constituted mutually with culture, and seen from a "worldly" perspective? What ideology underlies the experience of depression in the Brazilian, Chilean and North American culture? And at last: Which is the cultural and ideological meaning of depression in the contemporary world?
\end{abstract}

Keywords: Depression, critical psychopathology, worldly phenomenology.

En las sociedades occidentales se ha producido una disminución generalizada de las clásicas neurosis

Virginia Moreira, Universidad de Fortaleza - UNIFOR, Brasil.

La correspondencia relativa a este artículo deberá dirigirse a la autora: Universidade de Fortaleza - UNIFOR, Mestrado em Psicologia, Av. Washington Soares, 1321 Fortaleza - CE, 60811-341, Brasil. E-mail: virginiamoreira@unifor.br La autora agradece a Alejandra Pezoa, por la traducción al español de la versión orginal de este artículo, a Coral Calderón por su edición y a Angela Vasconcelos (Universidade de Fortaleza/Funcap) por la revisión final; a Renata Melo por la realización de las entrevistas brasileñas y coordinación del trabajo de campo en Brasil mientras desarrollaba la investigación en Boston; a Erika Moreno y Claudia Honorato, por la realización y transcripción de las entrevistas en Chile. En especial, agradece a Byron Good, por la interlocución, en Harvard Medical School, sobre las ideas planteadas en este artículo y a Irene Magaña, amiga querida y colaboradora en la Universidad de Santiago de Chile.

1 Este artículo fue presentado originalmente como conferencia en el IV Congreso Iberoamericano de Psicología, realizado en Santiago, Chile, 19-22 de Julio de 2004. Traducción al español por Alejandra Pezoa. edípicas, tales como fobias e histerias, y un aumento alarmante de la depresión, dependencia de drogas, desórdenes psicosomáticos y narcisistas de la personalidad, asociados al estilo de vida individualista, típico del mundo capitalista (Moreira, 2001; Moreira \& Sloan, 2002). Muchos de los síntomas explicados como existenciales, médicos o simplemente psicológicos, probablemente tienen orígenes socioculturales, tal como se encuentra demostrado en estudios transculturales en psicopatología (Aboud, 1998; Draguns, 1995; Kleinman \& Good, 1985; Marsella, 1993 y 1998; Marsella \& Yamada, 2000; Matsumoto, 1997; Moreira \& Boris, 2006; Moreira \& Coelho, 2003; Morris, 1998; Sam \& Moreira, 2002; Sartorius, 1983; Schumaker, 1996; Schumaker \& Ward, 2001; Tatossian, 1997 y 2006).

A pesar de que la depresión ha sido estudiada desde los tiempos de los filósofos griegos (quienes la llamaban melancolía) ésta se ha convertido en la enfermedad mental representativa de la postmodernidad; podríamos incluso decir que es la enfermedad 
de moda en el mundo occidental, llegando a alcanzar niveles de epidemia (Berlinck, 2000; Ehrenberger, 2000; Schumaker, 2001). La depresión es entendida de formas diferentes y contradictorias: como un disturbio narcisista típico de la sociedad occidental, como un desorden cerebral de producción de serotonina o simplemente desde una perspectiva ontológica. Su significado oscila entre los polos cultural y biológico, siempre en una perspectiva dicotómica en el abordaje psicopatológico, basado en un pensamiento dualista, que confirma la ideología individualista típica del mundo occidental, en la cual la enfermedad mental es considerada únicamente en su origen individual (Kleinman, 1995; Moreira, 2005a; Moreira \& Sloan, 2002).

En el libro "Más allá de la persona: Hacia una psicoterapia fenomenológica mundana", publicado en Chile por la Editorial de la Universidad de Santiago de Chile, critiqué el humanismo antropocéntrico en la psicología y en la psicopatología y, basándome en la fenomenología de Merleau-Ponty, propuse una perspectiva mundana para la psicología y la psicopatología (Moreira, 1998, 2001, 2004, 2005a y 2005b; Moreira \& Callou, 2006). Esta perspectiva incluye necesariamente la dimensión cultural, así como las dimensiones endógena y situacional, que existen en mutua constitución.

Entiendo la cultura en su sentido antropológico, como la intersección entre el significado y la experiencia, tal como es definido por Kleinman \& Good (1985). La experiencia depresiva, comprendida de esta manera, incluye un abordaje crítico del problema (Fox \& Prilleltensky, 1996; Prillelstenky, 2001), que tenga en cuenta su complejidad política e histórica, como producto del contexto cultural particular en el cual emerge. Como sugiere Kleinman (1995), eso significa que la depresión, así como otras enfermedades psicopatológicas, deberá ser estudiada como una forma de experiencia cultural surgida no sólo a partir de estructuras y procesos clínicos, sino también a partir de factores políticos y sociales. Desde este punto de vista, la depresión se caracteriza tanto por la universalidad de su ocurrencia en diferentes culturas a lo largo de la historia de la humanidad, como por su diferenciación de una forma singular de expresión y ocurrencia en cada cultura particular en el mundo contemporáneo.

Este artículo es parte de un proyecto de investigación acerca del "Significado de la depresión en el mundo contemporáneo: Un estudio crítico cultural en Brasil, Chile y Estados Unidos" (Moreira, 2002b) desarrollado en el período 2002-2006, en la
Universidad de Fortaleza, Brasil, en el Departamento de Medicina Social de Harvard Medical School, en Estados Unidos, contando con la colaboración en Chile, de la Prof. Irene Magaña, de la Universidad de Santiago de Chile. Se trata de una investigación cualitativa fenomenológica con 71 sujetos colaboradores en los tres países; en estos momentos, se encuentra en su etapa final de redacción de los resultados. En este artículo presento algunas reflexiones iníciales, a partir de este trabajo de investigación, a la luz de estudios anteriores en el ámbito de la Psicopatología Crítica (Moreira, 2002a, 2005a, 2005b, 2005c).

Entendiendo la depresión de forma mundana, en la intersección entre el hombre y el mundo, siendo su etiología antropológica, sociológica y política, y no sólo individual-biológica y/o psicológica - tal como argumentaré en un encuadre de la Psicopatología Crítica. Partiendo de esta premisa, reflexionaré acerca de las siguientes preguntas: ¿Cuál es el significado actual de la depresión como manifestación psicopatológica, constituida mutuamente con la cultura a partir de una perspectiva mundana?; ¿Qué ideología sustenta la experiencia de la depresión en las culturas brasileña, chilena y norteamericana?; y por último, ¿Cuál es el significado ideológico y cultural de la depresión en el mundo contemporáneo?

\section{El Encuadre Mundano de la Psicopatología Crítica}

En el libro "Personalidad, ideología y psicopatología crítica”, realizado en co-autoría con Tod Sloan, publicado el año 2002 en Brasil por la Editorial Escuta, propongo una Psicopatología Crítica, que al tener como base una mirada fenomenológica mundana de la psicopatología, busca comprenderla en sus múltiples contornos.

La idea de múltiples contornos fue desarrollada por Merleau-Ponty (1966) en "La Doute de Cézanne", donde el filósofo hace una analogía entre su filosofía y la pintura de Cézanne, mostrando que en esa pintura se puede constatar que lo real se mezcla con lo imaginario, deformando así la realidad. La pintura de Cézanne retrataría el pensamiento de Merleau-Ponty, ya que muestra la ruptura definitiva de las dicotomías, a través del reconocimiento de las ambigüedades inherentes al ser humano, con la idea de una realidad en movimiento que tiene múltiples contornos, mezclándose con el mundo, es decir, mundana. En estudios anteriores (Moreira, 1998, 2001, 2005a, 2005b) utilicé esta idea de múltiples contornos para una comprensión 
fenomenológica mundana de la psicopatología. La Psicopatología Crítica retoma esta comprensión de la psicopatología a partir de los múltiples contornos para reflexionar acerca de su etiología, también con múltiples contornos, diversos orígenes que se mezclan, se entrelazan y se constituyen mutuamente, tal como ocurre en la pintura de Cézanne.

Se sabe que la psicopatología tradicional, desarrollada en el ámbito del pensamiento occidental, se inserta en una tradición dualista cartesiana, donde el hombre tiene un adentro y afuera, una dimensión social y otra individual, un mundo externo y un mundo interno. Estudios anteriores en el ámbito de la clínica psicológica y psiquiátrica fenomenológica muestran cómo la psicopatología tradicionalmente elige como objeto de estudio lo de adentro, lo individual, lo interno (Moreira, 2001, 2005a, 2005b; Tatossian, 1997, 2006; Tellenbach, 1967). El concepto de mundano con múltiples contornos en Merleau-Ponty $(1960,1964)$ rompe definitivamente con la dicotomía hombre/mujer-mundo, sujeto-objeto, individuosociedad, real-imaginario. Se trata de utilizar una lente cultural para entender la experiencia psicopatológica en su complejidad histórica, que incluye por ejemplo, la identificación de las situaciones de injusticia y desigualdades sociales como parte de su etiología. Tomemos por ejemplo - para entender esta premisa - el análisis de Kleinman, Das y Lock (1997) y Lira (2000) cuando se refieren al error de diagnosticar como estrés post-traumático situaciones de violencia política vividas por sus pacientes. No es que esas personas no estén sufriendo, por el contrario, sufren mucho, sin embargo, la patología mental aquí se inserta en el ámbito de la opresión y violencia social y no sólo en el de la psicología, tanto a nivel de diagnóstico como de tratamiento (todos los modelos "neutros" de psicoterapia son ineficientes para esta patología).

La etiología es entonces fundamental para una psicopatología crítica que desarrolle la lectura de la depresión que, a su vez, está constituida por contornos difusos. En estudios anteriores (Moreira, 2002a, 2005b) describí este proceso basado en tres dimensiones: endógeno, cultural y situacional. Estas tres dimensiones forman parte de la etiología, sin una demarcación exacta entre ellas, siempre en movimiento y constituidas mutuamente. Es decir, la depresión jamás tendrá un origen solamente cultural o endógeno o puramente situacional. Estas tres dimensiones estarán siempre entrelazadas a través de múltiples contornos en la constitución de la depresión en cuanto fenómeno mundano.
A partir de este encuadre, veamos entonces, algunos significados posibles de la depresión en el mundo contemporáneo.

\section{La Depresión Como una Patología Culturalmente Delimitada (Cultural-Bound Disorder) ${ }^{2}$}

"Son muchas cosas... tengo que trabajar, cuidar de la casa, cuidar de mi padre que está enfermo, ir al banco, resolver cosas en la escuela de mi hijo, $y$ yo soy sola, no tengo nadie para ayudarme...".

"No sé, yo creo que todo el día desde que te levantai estay sometido a una forma de vida $x$, de una manera neoliberal que oprime tu poca libertad y te coarta a veces las cosas de manera de que tení que remunerar, tení que tener tu plata, tení que empezar a meterte en una historia que no te gusta, a tomar la micro desde que salis de tu casa, comprar el pan o cuestiones, que de repente son cosas chicas pero que después se empiezan a acumular, de repente a tu polola no la puedes invitar al cine, no tení como divertirte, a veces no podi estudiar por eso, de repente uno no puede estudiar pero hay gente que no puede comer, son problema como de personas terceras que de repente tu ni conocí y te encuentras con una realidad que creo que también te afecta. La sensibilidad misma que uno tiene, igual le afectan todos los problemas. Entonces empiezas a ver de a poco y uno no dice lo que le pasa, al principio tampoco se siente deprimido, pero en un momento en que uno colapsa al ver que la cuestión es demasiado, muy rápida y uno está muy lento."

La cultura, como uno de los determinantes en la constitución del sujeto, siempre constituirá los estados psicológicos normales o patológicos de ese sujeto, incluyendo la depresión. En la medida en que los valores culturales se diferencian de una sociedad

\footnotetext{
2 Originalmente las citas que se incluyen en este artículo estaban en portugués, castellano e inglés y fueron todas traducidas al castellano. Las personas entrevistadas son pacientes del Caps (Centro de Atenção Psicológica) en Fortaleza, Brasil, del CAP (Centro de Atención Psicológica) de la USACH, en Santiago, Chile y en el Center House, en Boston, Estados Unidos, que participaron de la investigación transcultural coordinada por la autora entre 2001 y 2004: "El significado de la depresión en la contemporaneidad: Un estudio crítico-cultural en Brasil, Chile y Estados Unidos" (VRPPG 02130 Universidade de Fortaleza - DSM - Harvard) que investigó la experiencia de la depresión, con el propósito de comprender y contrastar significados culturales e ideológicos de la depresión en los tres países. Participaron 77 personas, que contestaron a una entrevista abierta y dieron su consentimiento informado para la publicación de las citas que aquí se incluyen.
} 
a otra, los síntomas de la depresión también varían de una cultura a otra. Aunque la experiencia vivida en la depresión sea la misma, la expresión de ésta variará dependiendo de la cultura donde se manifieste (Kleinman \& Good, 1985; Matsumoto, 1997; Moreira, 2001; Moreira \& Boris, 2006; Moreira \& Sloan, 2002; Morris, 1998; Schumaker, 2001; Tatossian, 1997). Desde el punto de vista clínico, el diagnóstico de depresión está íntimamente asociado a disforia, caracterizada por la falta de placer, tristeza, falta de entusiasmo, estados de ánimo cuestionables como síntomas psicopatológicos, como bien recuerda una perspectiva transcultural del problema (Kleinman \& Good, 1985). Una serie se investigaciones transculturales argumentan cómo la disforia es interpretada y socialmente organizada de diferente forma en las diversas sociedades, poniendo énfasis en encontrar los factores psicológicos en la perspectiva occidental de la depresión, en contraposición al relativo énfasis en los factores somáticos en las sociedades no occidentales (Kleinman \& Good, 1985; Schumaker, 2001; Tatossian 1997, 2006). Así la patología de la depresión y la disforia no son sólo interpretadas diferentemente en sociedades no occidentales y en diversas culturas, son constituidas de una manera fundamentalmente diferente en distintas formas de realidad social, lo que lleva a los antropólogos a argumentar acerca de la necesidad de una descripción cuidadosa de los significados regionales, en una perspectiva transcultural (Kleinman \& Good, 1985; Moreira, 2002a; Moreira \& Boris, 2006).

Entendiendo que las enfermedades mentales están íntimamente asociadas a culturas específicas, algunos autores actuales han tenido en cuenta su alta incidencia llegando a considerar la depresión como una "bound-culture", síndrome de la sociedad contemporánea occidental, es decir, un síndrome característico de esta sociedad occidental (Moreira, 2003a; Moreira \& Sloan, 2002; Schumaker, 2001). Esta afirmación defiende la idea de que la cultura occidental actual es constituyente de la depresión, o más que esto, en un lenguaje fenomenológico merleau-pontyano, la depresión y la cultura contemporánea existen en mutua constitución; estaríamos hablando entonces de una depresión mundana, como concepto crítico.

Veamos de qué formas el mundo contemporáneo occidental y la depresión estarían existiendo en mutua constitución y, en la perspectiva planteada por la Psicopatología Crítica (Moreira, 2002a, 2003a y b y 2005b) qué significados asumiría la depresión en este contexto.

\section{La Depresión como Melancolía}

"En mi trabajo vivo siempre situaciones de estrés, conflicto, desgaste, lo que me causa mucho cansancio, falta de sueño, porque cuando me voy a dormir me quedo preocupado pensando en lo que debo hacer para conseguir eso, evitar aquello..."

“...con mucha competitividad, dedicado al trabajo, dedicado a la parte del éxito, y con poca preocupación de otros aspectos de la vida, lo que hizo que efectivamente me fuera bastante bien profesionalmente, económicamente, pero el resto de mi vida se convirtió en un desastre, entonces, yo ahi fui forjando, armando depresión..."

“Esta es mi 'depresión de trabajo”.... Yo tengo que ser el mejor."

Al conjunto de síntomas que hoy llamamos depresión en el Occidente o neurastenia en China (Kleinman, 1986) los antiguos llamaron melancolía (bilis negra), vocablo derivado del griego y encontrado por primera vez en el Corpos Hipocraticum, que hace derivar la melancolía de determinadas discrasias de sangre y de los humores: la sangre se mezcla con bilis y flema (Tellenbach, s/f).

El análisis de Tellenbach de las características de la melancolía entre los griegos lo lleva a reforzar su tesis sobre los typus melancholicus, temática central de muchos años de estudio en psiquiatría fenomenológica. Según estas investigaciones, existiría en el mundo occidental contemporáneo un tipo melancólico, una personalidad propensa a la depresión que, al parecer, se hace cada vez más presente en la contemporaneidad. El typus melancholicus descrito por Tellenbach (1967, s/d) se caracteriza básicamente por el espíritu del orden, que predomina en todos los dominios de la personalidad, acompañado por un alto grado de autoexigencia y tendencia a la comunicación simbiótica. La autoexigencia exagerada del tipo melancólico puede ser también comprendida como una tendencia a sustituir la identidad del yo por una súper identificación al papel social (Tatossian, 1997, 2006), sea en el ámbito profesional o en el ámbito íntimo. La vida del tipo melancólico está sometida al primado del trabajo y del deber a través de una aparente conciencia moral aguda que es, antes que todo, "guardia de un orden previsto" (Moreira, 2002a).

Una reflexión del punto de vista ideológico de este tipo de personalidad muestra que está perfectamente bienvenida y adecuada a un sistema social que 
espera exactamente la obediencia del orden social y económico capitalista competitivo. El "trabajólico"3 es una personalidad postmoderna cada vez más frecuente, muchas veces transformada en verdadera patología mental del orden de las compulsiones. La compulsión al trabajo en la sociedad contemporánea busca llenar el vacío generado por el individualismo (Bauman, 1998; Costa, 2000; Lipovetsky, 1996; Moreira, 2003a; Moreira \& Sloan, 2002).

Las características del tipo melancólico, tan valorizadas socialmente, de alguna forma rescatan el pensamiento de los antiguos griegos: este es considerado genial, como en la perspectiva de Aristóteles. El melancólico sería considerado el "buen hombre" de las sociedades occidentales - aquel tipo ideal (Prilleltensky, 2001). Eso tiene evidentemente un carácter ideológico. Es "genial" quien trabaja como loco, aunque no vea sentido en ello, actuando de forma "domesticada", usando una terminología de Paulo Freire (2000/1996). El tipo melancólico estaría siguiendo lo que Sloan (1996) llama el "impulso ideológico", desarrollando comportamientos que le generan profundo sufrimiento psíquico, pero que atienden a una ideología incorporada de lo que debe ser así y por eso se mantienen (Moreira \& Sloan, 2002). Obediente al orden social vigente, el tipo melancólico parece ser perfectamente adecuado a la actual cultura occidental competitiva, siendo, por lo tanto, estimulado y aplaudido.

\section{La Depresión Como un Desorden de los (Des)Afectos}

"Entonces, mi cabeza dejó de servir. Fue cuando me vino la depresión, yo no tenía más ganas de vivir.. no quería ducharme, me encerraba en la habitación y no quería ver a nadie. La depresión no se la puede ver a la persona en el rostro y por eso piensan que no es una enfermedad grave, pero lo es porque sólo quien sabe lo que es una depresión es quien la tiene, porque nosotros nos sentimos con la cabeza confusa, no dormimos, nos sentimos inútil, i¿a que si?!”

“... mi modo de vida... con mucha competitividad, dedicado al trabajo, dedicado a la parte del éxito, y con poco preocupación de otros aspectos de la vida, lo que hizo que efectivamente me fuera bastante bien profesionalmente, económicamente, pero el resto de mi vida se convirtió en un desastre,

3 Aquel que es dependiente del trabajo, analogía hecha con alcoólatra. entonces, yo ahi fui forjando, armando depresión, yo no sabía que tenía depresión, cuando me sentía mal, yo no sabía lo que era, hasta que al final afectó a mi matrimonio y todo el cuento, y ahi yo recurría ayuda psicológica, siquiátrica y ahi yo me di cuanta que yo estaba deprimido, y hacía cosas porque estaba deprimido, entonces, el modo de mi vida me hizo forjar depresión..."

"Yo me cuido porque yo sé qué tipo de estilo de vida tengo que vivir para permanecer libre de mi depresión... mi respuesta para esto es hacer gimnasia y mantener los niveles de stress bajos..."

La depresión es considerada un desorden de los afectos y así se clasifica en el actual DSM-IV, en contraste con los desórdenes del pensamiento, como por ejemplo, la esquizofrenia. La división entre afecto y pensamiento es fruto de una forma dicotomizada de pensar la psicopatología (Moreira, 1998, 2002a). Sin embargo, teniendo en vista que la depresión, de hecho, privilegia alteraciones de carácter afectivo como tristeza, desesperanza, falta de ganas de vivir, es interesante pensar en qué medida la cultura contemporánea occidental influencia los afectos, o mejor dicho, la cognición que tenemos de los afectos (Moreira \& Freire, 2003; Schumaker \& Ward, 2001).

El desvirtuamiento de los afectos en la contemporaneidad aparentemente es parte de la génesis de la epidemia de la depresión en que vivimos. El amor por sí mismo sustituye al amor a la comunidad, amor a un ideal o al amor religioso por el prójimo. La sociedad actual en redes (Castells, 2000) confunde aún más los afectos humanos, con el Internet que instituye nuevos comportamientos compulsivos de "conectarse" al otro, manteniéndose, al mismo tiempo distante del otro lado de la pantalla. La indiferencia o el desafecto por el otro tiene un significado ideológico, en la medida en que mantienen situaciones de indiferencia social mediante el sufrimiento humano, perpetuando las enormes diferencias sociales, marca registrada del mundo contemporáneo. La depresión debería entonces su auge al vaciamiento de los significados afectivos de la vida humana, parte de un sistema de valores morales que se perdieron. Contradictoriamente, el sufrimiento psíquico ligado al vacío lleva a la búsqueda inalcanzable de intimidad y mucha gente termina cayendo en la "trampa" de los medicamentos antidepresivos (que, aunque indicados en algunos casos, son utilizados masiva e indiscriminadamente en nuestros días, tal como discutiré más adelante), ya que, cuánto más se busca, 
menos se consigue sentirse acompañado, dado que lo que se busca está en el plano de lo idealizado, no en el plano de la realidad. La etiología de la depresión estaría más directamente asociada a un orden social de los desafectos que a un desorden de los afectos (Moreira 2003a; Moreira \& Freire, 2003; Moreira \& Sloan, 2002).

\section{La Depresión Como Falta de Poder}

"Hoy día, la persona con 48 años de edad es totalmente inválido para el trabajo. Las personas no quieren más. Entonces nos quedamos con un camino muy estrecho. Cada día el camino se va estrechando más (...) hasta que llega la depresión”.

"Porque siempre estoy así, con depresión (llora) $y$ digo... voy a ir... pero me voy a poner a llorar, o no quiero que me vea así, que el otro día pensaba y miraba, ipensar que yo era como ella!, mujeres activas, y yo ahora, soy así como usted me ve, enferma... no sé si le va a servir esta entrevista porque estoy mal yo ahora o ¿eso es lo que quería ver usted?"

"Cuando me despierto y tengo que hacer cosas y tengo depresión yo no quiero levantarme, no quiero la rutina diaria, no quiero hacer nada, no tengo energía, no tengo ambiciones, no tengo entusiasmo en mi vida, quiero decir no puedo hacer esto hoy dia...."

Ya en su clásica publicación acerca de Cultura $y$ depresión, Kleinman y Good (1985) sugieren la cuestión del poder como prioridad en la investigación transcultural de la depresión: "El estudio de la enfermedad de la depresión con relación a los contextos locales de poder, tiene un importante potencial para desarrollar nuestra comprensión de la producción y manutención social de la depresión" (p. 498). Estos autores toman como base los múltiples resultados de investigaciones transculturales que muestran que la depresión, en la gran mayoría de las sociedades, tiene prevalencia entre las mujeres, individuos que ocupan estatus sociales de relativa falta de poder y personas económicamente marginadas.

La sensación de impotencia o de falta de poder también se hace presente en la idea de que no depende del sujeto cambiar el orden de las cosas; nada, o muy poco depende de él en la sociedad vigente. La impotencia o la falta de ejercicio de poder es parte de una ideología fatalista (Freire, 2000/1996), que da lugar a variadas formas emocionales de desesperanza, desánimo y desmotivación, unidas a posibles mani- festaciones de la depresión. El cuadro se agrava, ya que impotente frente al mundo en que vive e incapaz de luchar con sus propias angustias, este ser humano integrante de la clase media va a vivenciar una total falta de poder cuando busque a los especialistas que tratan la depresión. La depresión pasa a ser vivida entonces como una total falta de poder, el individuo está enfermo, tiene que ser tratado, y sólo los profesionales especialistas psi saben tratar (Prilleltensky, 2001). Mientras se cristalizan sus proyectos o sus sueños quedan estancados, su trabajo se ve afectado y todo queda de lado "para cuando esté curado". La angustia frente a la violencia social, la pobreza y las desigualdades sociales (porque la indiferencia o el desafecto son ideológicamente patológicos) queda anestesiada junto con las otras angustias por los eficientes efectos de los ansiolíticos y de los antidepresivos (Moreira, 2003a; Moreira \& Sloan, 2002).

Es así que de diferentes maneras y en diferentes clases sociales, la epidemia de la depresión en el mundo contemporáneo occidental se delinea como expresión de la falta de poder que vive este ser humano que se piensa como simple individuo, impotente frente a su propio mundo, que lo oprime cotidianamente.

\section{La Depresión Como Incapacidad de Vivir Significativamente}

“... Nuestra vida es muy difícil, yo lo veo en casa, hay dias en que no hay nada para comer y no hay dinero para nada. Sufrimos viendo nuestros hijos con hambre (...) Sin poder hacer nada".

"He..... demasiado....... ¿cómo te diría?...... mala o sea... una vida vacía, sin nada que realmente me llamara, me llamara la atención, que fuese algo bueno para mi, no tenía cero responsabilidades.... eso....... no quería atarme mucho a muchas cosas..... era una vida que llevaba antes yo de caer en depre.... y después ya..... como ahi empecé como a ver.."

"No puedo vivir realmente... Para qué? No me importa vivir."

La autorreflexión necesaria para vivir significativamente tendrá características de emancipación, concientización, potenciación, liberación y desideologización. La psicopatología se constituirá exactamente por su contrario, es decir, en alineación y despotenciación ideológica a través de un proceso de inmovilización reflexiva (Moreira, 2003a; Moreira \& Sloan, 2002; Sloan, 1997). 
Como vimos, la depresión se ha asociado al individualismo, a la falta de sentido, al vacío que caracteriza la vida en la sociedad postmoderna. Las personas trabajan, aunque no saben por qué trabajan, viven, aunque no saben porqué o para qué vivir pues actúan de forma automática, siguiendo impulsos que, frecuentemente, son impulsos ideológicos que constituirán comportamientos ideológicamente determinados.

La incapacidad de vivir significativamente tiene que ver con la incongruencia entre el sentir, el pensar y el actuar, que es producida por la incapacidad de experienciar simultáneamente los significados contradictorios asociados con prácticas discursivas culturalmente conflictivas. Este proceso se traduce en el proceso de despotenciación que caracteriza a todas la psicopatologías y a la depresión en particular (Moreira, 2003a; Moreira \& Sloan, 2002).

Es así que la pérdida de un sistema de valores éticos y morales en las sociedades contemporáneas, contribuyen al desarrollo de la depresión. El compromiso con el sueño y el proyecto de una vida en un mundo mejor son incompatibles con el nihilismo, característico de la ideología fatalista (Freire, 2000/1996), que es parte de tantos de los cuadros depresivos actuales, donde los pacientes son literalmente pacientes, en el sentido de la palabra: pasivos, prisioneros de su propia situación.

\section{La Depresión Como un Disturbio de Serotonina}

"Gracias a Dios, estoy aquí tomando una medicina para mejorar, ¿sabes? Hay días que me faltan las medicinas y me tiemblan todas las carnes y mientras no me tomo ese tal del 'diazepan' que la Doctora me recetó, yo tomo dos por la mañana y uno por la noche, si no me los tomo, se me faltan caer al suelo las carnes, ya no siento más nada, necesito tomar la medicina para controlar los nervios, ¿sabes?"

"Mi modo de vivir, no sé poh la depresión te consume, porque una no, no tiene fuerzas pa' nada, pa' ninguna cosa, ni siquiera de abrir los ojos, y cuando al menos con pastilla y todo, me siento bien poh, me siento más liviana, no pienso en nada, $y, y$ vivo mi vida normal no más poh, pero sin pastillas soy un fracaso..."

"Tengo que tomarme los remedios para sentirme mejor (...) todos los dias, todas las noche y entonces me voy sintiendo mejor."
La idea de que la psicopatología -la depresión en este caso- es un problema solamente individual, perpetúa el poder de la visión biomédica (Birman, 1999; Marsella \& Yamada, 2000). No pretendo negar aquí la existencia de una dimensión bioquímica en la etiología de la depresión, ni el enorme valor de los descubrimientos recientes en el campo de la psicofarmacología, que representan sin duda un gran avance del conocimiento biomédico, que es necesario y útil en el combate del sufrimiento psíquico. Cabe denunciar el uso comercial irresponsable, indebido y exagerado de drogas que, mal administradas, hacen más mal que bien. No se puede desconocer que en el panorama actual del abordaje y tratamiento de enfermedades mentales, este modelo bioquímico prevalece (Marsella \& Yamada, 2000) asociado a intereses económicos de laboratorios multinacionales. Se trata el síntoma, dejando de lado la etiología, lo que más de una vez, está relacionado a una ideología de tipo organicista e individualista que, como dice Silva (1999) corresponde a la instauración de la propiedad privada, característica fundamental del orden socioeconómico capitalista.

La utilización del remedio, prescrito para "arreglar" las alteraciones de la serotonina, deja ver una forma de ser postmoderna, donde se requiere respuestas y soluciones inmediatas para los problemas. Morris (1998) hace una analogía entre el gasto público en boga por conceptos rápidos en una sociedad "fast-todo" ("todo-rápido"), que busca curas instantáneas a través de drogas. Sin embrago, la así llamada revolución en psiquiatría, que entiende la depresión como una alteración bioquímica, no es una completa victoria para los pacientes. Las píldoras son más fáciles y más baratas que una psicoterapia, por ejemplo, y mucho más simples aún de lo que se piensa en términos de salud psicológica comunitaria, lo que exigiría medidas macro-sociales preventivas. Pero el tratamiento de una disfunción neuroquímica a través de drogas apenas corrige un desequilibrio biológico. No explica cómo y porqué este desequilibrio ocurrió, ni previene contra recaídas (Moreira, 2002a y 2002b).

La ideología de la serotonina ignora la constitución también socio-cultural de la depresión y la propaganda de psicofármacos mágicos estimula el diagnóstico de la depresión para el sufrimiento psíquico. Existen sí casos en que la persona está realmente enferma y se beneficia enormemente del tratamiento farmacológico como única alternativa de mejoría. Sin embargo, son muchos y cada vez más frecuentes los casos en que el diagnóstico es "adormecedor", o sea, se medica el sufrimiento psíquico como síntoma 
individual, cuando muchas veces se trata de un síntoma social y político, tal como ocurre en situaciones de violencia, corrupción, competencia o explotación social (Moreira, 2002a, 2002b, 2003a, 2005c).

Finalmente, además de transformar el sufrimiento humano en patología mental y de ignorar situaciones socioculturales de opresión social generadoras de sufrimiento psíquico, la ideología de la serotonina aún menosprecia los efectos colaterales y las consecuencias que los psicofármacos tienen en el equilibrio metabólico del propio organismo. La droga, que debería ser utilizada como último recurso, pasó a ser primera alternativa. Y lo que frecuentemente termina ocurriendo es que se trata bioquímicamente una experiencia humana que, en verdad se constituye culturalmente, por la sensación de falta de poder e incapacidad de vivir significativamente (Moreira, 2002a, 2002b).

\section{El Significado Ideológico de la Depresión}

En este artículo señalé sólo algunos de los posibles significados de la depresión en el mundo contemporáneo. Sin embargo, a partir de las reflexiones hechas a través de una lectura fenomenológica mundana, creo que se puede decir que es realmente imprescindible una comprensión desideologizadora de la depresión, utilizando este concepto tal como fue definido por Martin-Baró (1985), entendiendo ideología como ideas o imágenes que sustentan injusticias sociales promoviendo intereses particulares (Moreira, 2000, 2005b; Sloan, 1997).

Una psicopatología crítica buscará la comprensión ideológica de la situación del paciente que tiene el diagnóstico de depresión dentro de la estructura socio-histórica en que éste vive, se relaciona, trabaja y enferma. Es decir, se preguntará cuál es la función de la depresión en este contexto o en qué medida existe un grupo específico de la sociedad que tiene intereses en la existencia de esta enfermedad.

No es que no existan los casos de compromiso orgánico, ellos son frecuentemente incitados por los procesos de pobreza, lo que vuelve el tratamiento farmacológico necesario en muchos casos. Sin embargo, en algunas regiones de América Latina, el síntoma frecuentemente es mucho más social que psicopatológico y muchas veces el trabajo del asistente social o del líder político termina siendo mucho más importante que el del médico. Ningún medicamento tiene la capacidad de curar la pobreza: él funciona solamente como anestésico, entorpecedor o amortiguador social tal como es demostrado en investigaciones acerca de la dependencia a la benzodiazepina en mujeres pobres del Nordeste de Brasil (Oliveira, 2000). Los medicamentos sólo deberían ser utilizados en último caso, cuando todas las alternativas de tratamiento estuviesen realmente agotadas. Es un desafío moral y ético diario para el profesional del área de la salud mental, luchar con la psicopatología y la pobreza sin confundirlas (Moreira, 2003b; Moreira \& Sloan, 2002)

\section{Conclusión}

Una lectura fenomenológica mundana de la depresión indica que, si por un lado los modos de vivir narcisistas del mundo contemporáneo incentivan la depresión, por otro, se hace difícil identificar hasta qué punto se diagnostica la depresión de hecho o el simple sufrimiento psíquico. Muchas veces se prescribe un tratamiento para la tristeza, que es un sentimiento genuinamente humano, que es ontológico, no es patológico (Minkowvski, 2000).

La tristeza necesita ser vivida, elaborada y no anestesiada a través de drogas. La palabra "triste" está casi desapareciendo del vocabulario del sujeto postmoderno, cada vez expresa menos su tristeza como sufrimiento psíquico, se piensa cada vez más como alguien que está “deprimido", necesitando por lo tanto, tratamiento psi de toda orden. Y está ahí todo el mercado psi para tratarlo (¿o explotarlo?).

\section{Referencias}

Aboud, F. (1998). Health psychology in global perspective. Thousand Oaks: Sage.

Bauman, Z. (1998). O mal-estar da pós-modernidade. Rio de Janeiro: Zahar.

Berlinck, M. (2000). Psicopatologia fundamental. São Paulo: Escuta.

Birman, J. (1999). A psicopatologia na pós-modernidade: As alquimias do mal-estar da atualidade. Revista Latinoamericana de Psicopatología Fundamental, 2(1), 25-49.

Castells, M. (2000). Sociedade em rede. São Paulo: Paz e Terra.

Costa, J. (2000). Playdoier pelos irmãos. En M. R. Khel (Ed.), Função fraternal (pp.7-30). Rio de Janeiro: Relume-Dumará.

Draguns, J. (1995). Cultural influences upon psychopathology: Clinical and practical implications. Journal of Social Distress and the Homeless, 4, 89-114.

Ehrenberger, A. (2000). La fatigue d'être soi. Dépression et societé. Paris: Odile Jacob.

Fox, D. \& Prilleltensky, I. (Eds.) (1996). Critical psychology: An introduction. Thousand Oaks: Sage.

Freire, P. (2000/1996). Pedagogia da autonomia. São Paulo: Paz e Terra.

Kleinman, A. (1986). Social origins of disease and distress: Depression, neurasthenia and pain in modern China. New Haven: Yale University Press.

Kleinman. A. (1995). Writing at the margin: Discourse between 
anthropology and medicine. Berkeley: University of California Press.

Kleinman, A., Das, V. \& Lock, M. (Eds.). (1997). Social suffering. Berkeley: University of California Press.

Kleinman, A. \& Good, B. (1985). Culture and depression. Studies on the anthropology and cross-cultural psychiatry of the affect and disorder. Berkeley: University of California Press.

Lipovetsky, G. (1996). La era del vacio. Barcelona: Anagrama.

Lira, E. (2000). Reflections on critical psychology: Psychology of memory and forgetting. En T. Sloan (Ed.), Critical psychology: Voices for change (pp. 82-90). London: Macmillan.

Marsella, A. (1993). Sociocultural foundations of psychopathology: A history overview. Transcultural Psychiatry Research and Review, 30, 97-142.

Marsella, A. (1998). Toward a "global-community psychology": Metting the needs of a changing world. American Psychologist, $53,1282-1291$.

Marsella, A. \& Yamada, A. M. (2000). Culture and mental health: An introduction and overview of foundations, concepts and issues. En I. Cuéllar \& F. Paniagua (Eds.), Handbook of multicultural mental health (pp. 3-26). San Diego: Academic Press.

Martín-Baró, I. (1985). La desideologización como aporte de la psicología social al desarrollo de la democracia en Latinoamérica. Boletín de la Asociación Venezolana de Psicología Social, 8(3), 3-9.

Matsumoto, D. (1997). Culture and modern life. San Francisco: Brooks/Cole Publishing Company.

Merleau-Ponty, M. (1960). Signes. Paris: Gallimard.

Merleau-Ponty, M. (1964). L'oeil et l'esprit. Paris: Gallimard.

Merleau-Ponty, M. (1966). La doute de Cézanne. En M. MerleauPonty, Sens et non-sens (pp. 15-44). Paris: Nagel.

Minkowski, E. (2000). Breves reflexões a respeito do sofrimento. Revista Latinoamericana de Psicopatología Fundamental, 3(4), 156-164.

Moreira, V. (1998). Una comprensión de la psicopatología a partir de la fenomenología de Merleau-Ponty. Revista Chilena de Psicología, 19(1), 106-112.

Moreira, V. (2000). Ideologia e psicopatologia: Uma discussão fenomenológica transcultural. Revista Latinoamericana de Psicopatología Fundamental, 3(4), 80-91.

Moreira, V. (2001). Más allá de la persona: Hacia una psicoterapia fenomenológica mundana. Santiago: Universidad de Santiago de Chile.

Moreira, V. (2002a). Parte II-Psicopatologia Crítica. En V. Moreira \& T. Sloan, Personalidade, ideologia e psicopatologia crítica (pp. 109-248). São Paulo: Escuta.

Moreira, V. (2002b). The meaning of depression in the contemporary world: A critical-cultural study in Brazil, Chile and the United States. CAPES/Fulbright Research Project, Harvard Medical School-Universidade de Fortaleza (VRPPG02130).

Moreira, V. (2003a). The ideological meaning of depression in the contemporary world. International Journal of Critical Psychology, 9, 143-159.

Moreira, V. (2003b). Poverty and psychopathology. En S. Carr \& T. Sloan, Poverty and psychopathology: From global perspective to local practice (pp. 69-86). New York: Kluwer Academic/Plenum Publishers.

Moreira, V. (2004). O método fenomenológico de Merleau-Ponty como ferramenta crítica na pesquisa em psicopatologia. Psicologia: Reflexão e Crítica, 17(3), 447-456.

Moreira, V. (2005a). Ecology in the multiple contours of psychopathology. Revista Latinoamericana de Psicopatologia Fundamental, 8(1), 54-63.

Moreira, V. (2005b). Critical psychopahtology. Radical Psy- chology, 4(1). Recuperado desde: http://www.radpsynet. org/journal/vol4-1/moreira.html

Moreira, V. (2005c). ¿Enfermedad mental o pobreza? Una intervención clínica en la perspectiva de la psicopatologia crítica. En J. L. Sigall, Temas selectos en orientación psicológica: Creando alternativas (pp. 63-73). México: Editorial El Manual Moderno.

Moreira, V. \& Boris, G. (2006). O corpo vivido na esquizofrenia, Latin American Journal of Fundamental Psychopathology On-line, 6(1). Recuperado desde: http://www.fundamentalpsychopathology.org/?s=89\&c=277

Moreira, V. \& Callou, V. (2006). Fenomenologia da solidão na depressão. Revista Mental, 4(7), 67-84.

Moreira, V. \& Coelho, N. (2003). La fenomenología de la experiencia esquizofrénica: Un estudio crítico entre las culturas de Brasil y de Chile. Terapia Psicológica, 21(2), 75-86.

Moreira, V. \& Freire, J. C. (2003). La dépression dans la postmodernité: Un désordre des affections ou l'ordre dês désaffections? En B. Granger \& G. Charboneau, Phénomenologie des sentiments corporals, Vol. II (pp. 111-118). Paris: Circle Hermeneutique.

Moreira, V. \& Sloan, T. (2002). Personalidade, ideologia e psicopatologia crítica. São Paulo: Escuta.

Morris, D. B. (1998). Illness and culture in the postmodern age. Los Angeles: University of California Press.

Oliveira, E. (2000). Saúde mental e mulheres: Sobrevivência, sofrimento psíquico e dependência química lícita. Sobral: UVA.

Prilleltensky, I. (2001). Cultural assumptions, social justice and mental health: Challenging the status quo. En J. Schumaker \& T. Ward (Eds.), Cultural cognition and psychopathology (pp. 251-266). Westport: Praeger.

Sam, D. \& Moreira, V. (2002). The mutual embeddedness of culture and mental illness. En W. J. Lonner, D. L. Dinnel, S. A. Hayes \& D. N. Sattler (Eds.), Online readings in psychology and culture. Western Washington University, Department of Psychology, Center for Cross-Cultural Research: http://www. wwu.edu/ culture

Sartorius, H. (1983). Trastornos depresivos en diferentes culturas. México: Organización Mundial de la Salud.

Schumaker, J. (1996). Understanding psychopathology: Lessons from the developing world. En J. Schumaker, Psychology and developing world (pp. 180-190). Connecticut: Praeger.

Schumaker, J. (2001). Cultural cognition and depression. En J. Schumaker \& T. Ward, Cultural cognition and psychopatho$\operatorname{logy}$ (pp. 53-66). Westport: Praeger.

Schumaker, J. \& Ward, T. (Eds.). (2001). Cultural cognition and psychopathology. Westport: Praeger.

Silva, A. (1999). Elementos para compreender a modernidade do corpo numa sociedade Racional. Cad. Cedes, 19(48), 7-29.

Sloan, T. (1996). Damaged life: The crisis of the modern psyche. New York: Routledge.

Sloan, T. (1997). Theories of personality. Ideology and beyond. En D. Fox \& I. Prilleltensky (Eds.), Critical psychology: An introduction (pp. 87-103). Thousand Oaks: Sage.

Tatossian, A. (1997). Psychiatrie phénomenologique. Paris: Acanthe.

Tatossian, A. (2006). Fenomenologia das psicoses. São Paulo: Escuta.

Tellenbach, H. (1967). Estudios sobre la patogénesis de las perturbaciones psíquicas. México: Fondo de Cultura Económica.

Tellenbach, H. (s/f). La melancolía. Visión histórica del problema: Endogeneidad, tipología, patogenia y clínica (traducción de la $2^{\text {a }}$ edición). Madrid: Morata. 